\title{
El arquitecto Melchor Cano y la teoría de la ciudad
}

\author{
M. ${ }^{a}$ Dolores Antigüedad del Castillo-Olivares
}

En los trabajos que se han ocupado del estudio de la obra de Melchor Cano como arquitecto mayor de la ciudad de Sevilla, falta el análisis detallado de su labor como urbanista, de su capacidad para configurar espacial y arquitectónicamente la ciudad. Esta mutilación de la figura de Cano puede achacarse a su relación con don José Manuel de Arjona y Cubas, asistente de la ciudad de Sevilla de 1825 a 1833 y a quien se ha atribuido habitualmente la iniciativa urbanizadora y de regulación de la ciudad, cuando es, a nuestro juicio, la colaboración entre ambos la que da lugar a una serie de realizaciones concretas que más tarde comentaremos.

Melchor Cano nació en Madrid en 1794 y con veinticinco años de edad era aprobado como arquitecto en la Academia de Bellas Artes de San Fernando de Madrid el 28 de noviembre de $1819^{\prime}$. Tres años después, en 1822, presenta a la Academia de San Fernando el discurso para ser aprobado como académico de mérito en la institución, categoría que obtiene el 14 de abril de ese mismo año ${ }^{2}$ con la lectura del discurso titulado "Cuáles deben ser las miras del arquitecto en la formación de una ciudad capaz de seis mil vecinos, explicando con toda claridad la mayor hermosura y carácter de los edificios según sus destinos sin per-

1 Archivo Academia de Bellas Artes de San Fernando. Registro de Arquitectos Aprobados. Sig. Libro 3/154 (desde ahora A.A.B.A.S.F.).

2 A.A.B.A.S.F. Libro de Académicos de Mérito (1753-1845), sig. 3/18. Consta que don Melchor Cano, natural de Madrid y maestro arquitecto, es creado académico de merito por la Arquitectura en 14 de abril de 1822. 
der de vista la comodidad y reglas principales de policía" ${ }^{3}$. Nuestro interés al iniciar un comentario del discurso es demostrar que la formación profesional de Cano incluye un interés por los temas urbanos y que este interés desempeñará un papel decisivo en su obra posterior.

\section{UN DISCURSO ACADÉMICO}

El discurso comienza con la justificación de la existencia de la ciudad por la necesidad que tienen las familias de defenderse y apoyarse mutuamente y "asegurar su vida, personas y bienes bajo la protección de las leyes y de la autoridad pública".

Hace referencia a las ciudades antiguas de Atenas, Palmyra, Roma, etcétera, con casas, palacios y templos, además de obras de conveniencia pública como puentes, avenidas, plazas públicas, foros, mercados, termas, circos y anfiteatros. Esto marca una diferencia con las ciudades modernas: "En aquéllas se reunia todo lo que podía contribuir a las delicias de la vida, a engrandecer el espíritu y a la salud del cuerpo. Mas en las modernas, aun las más populosas, ¿qué es lo que se advierte sino una gran masa más bien destinada para encerrar a los hombres que para proporcionarles los dulces placeres de la sociedad?". El texto es un reflejo del pensamiento que prevalece en la cultura europea desde el siglo XVIII, al considerar la antigüedad como el momento en que el hombre vivía feliz, al contrario que en el momento actual donde el hombre ha perdido su libertad frente al progreso; el concepto es una muestra del pensamiento romántico ya presente.

Las ciudades antiguas sirven de modelo para que un arquitecto encargado de la formación de una ciudad consiga que ésta reúna salubridad, comodidad y hermosura. Éstos son los tres principios esenciales que recomiendan Vitruvio y Alberti, y que fueron recogidos por Benito Bails en su libro De la arquitectura civil, aunque en esta tríada la "salubridad» ha sustituido a la "perpetuidad y firmeza» propuganada por estos autores ${ }^{4}$.

El texto del discurso pertenece al Archivo de la Academia, manuscrito 310-18/3.

“ Marco Vitruvio Polión, Los Diez Libros de Arquitectura. Traducción y comentarios de José Ortiz y Sanz. Madrid, 1787, lib. I, capítulos 2 y 3. Ed. facsímil, Akal, 1987. LEON Battista Alberti, Los Diez Libros de Architectura de Leon Baptista Alberto traducidos del latin en romance. Madrid, Alonso Gómez, 1582 (libro I, cap. 2). Benito BAILS, De la arquitectura civil. Vol. IX de Elementos de Matemáticas. Joaquin Ibarra. Impresor de Cámara de S. M., 1783. Ed. facsímil, Murcia, 1783, vol. II, pág. 11. 
Siguiendo con el discurso, Cano expone que el sitio elegido para asentar la ciudad debe ser de aire sano y alegres vistas, de temperaturas moderadas y sin humedad. Las vistas deben ser variadas y la orientación aconsejable es al mediodia, con un río al mismo lado para que los vientos norte y levante disipen los vapores. Este planteamiento está sacado de la Arquitectura civil de Bails, aunque es un concepto tradicional en los arquitectos desde Vitruvio.

La ciudad debe tener una planta hexagonal a fin de que los diferentes cuarteles estén más inmediatos, haya menos distancia de unos a otros, se comuniquen mejor y la policía se ejercite con más facilidad. Aunque el planteamiento teórico es el mismo que Bails expresa en su texto, la figura hexagonal para la ciudad nueva tiene un origen antiguo: León Battista Alberti, en su tratado De re aedificatoria (1485), y otros tratadistas del Renacimiento, como Francesco di Giorgio Martini, en sus ciudades fortificadas, se inclinaron por la planta hexagonal ${ }^{5}$ (figs. 1 y 2 ). En el siglo XVIII se diseñó un contorno hexagonal para la ciudad siciliana de Granmicheli, que el virrey de Sicilia, Carlo Carafa, fundó como núcleo agrícola. Este modelo de ciudad centralizada en 1822, fecha en que se redacta el discurso, parece más una referencia erudita que un planteamiento utilitario por parte de Melchor Cano (fig. 3).

Fuera de la ciudad se colocarán los cementerios, lavaderos, etcétera. Cada uno de los lados del hexágono tendrá una puerta de entrada a la población, delante de la cual se formará una plaza semicircular, de la que partirán caminos con el ancho suficiente para que permita el desahogo a los viajeros. A cada lado de este camino se harán otros dos más pequeños para la gente de a pie, limitados todos ellos por una fila de árboles que además de adornar defenderán del sol. La idea, como podemos ver, no es nueva, habia sido expuesta ya por Palladio y recogida más tarde por Bails ${ }^{6}$.

A una prudente distancia de la cludad, siguiendo los caminos, se harian grandes plazas donde estarían establecidos los paradores, casas

${ }^{5}$ "Pero si pudiésemos escoger el sitio a nuestro arbitrio, haríamos nuestra población de figura hexágona o pentágona, con lo que estarian sus barrios inmediatos unos a otros, sería más fácil entre ellos la comunicación, y también la execución de las providencias políticas". BENITO BAILS, De la arquitectura civil, pág. 22.

La planta poligonal con plaza central hexagonal se empleó en la ciudad de Palma Nova (1593), atribuida a Scamozzi. Su planta aún se conserva en buen estado.

'Libros I y III de Andrea Palladio. Traducidos por F. de Praves, de Valiadolid, 1625, cap. II, pág. 9. Ed. facsimil, Valladolid, 1986. B. BAlls, obra citada, pág. 22. 


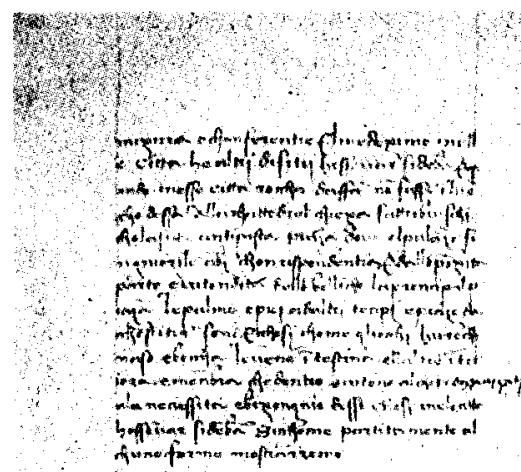

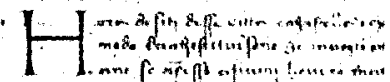

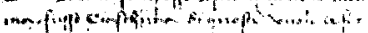

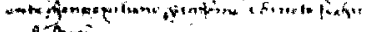
a 2 pres

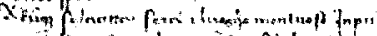

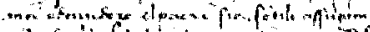

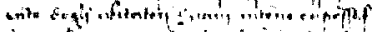

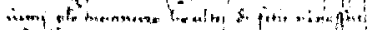
$A_{\text {in }}^{*}$ if

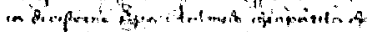

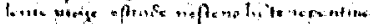

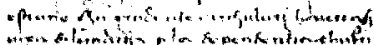

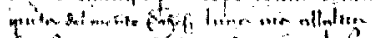

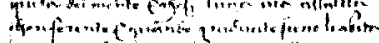

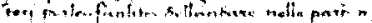

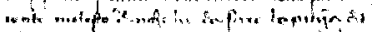

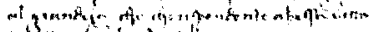

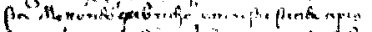

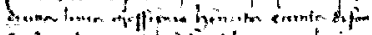

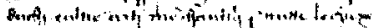

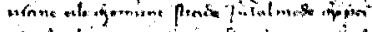

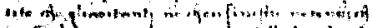

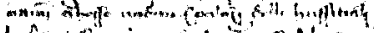

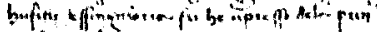
in mente pisis?

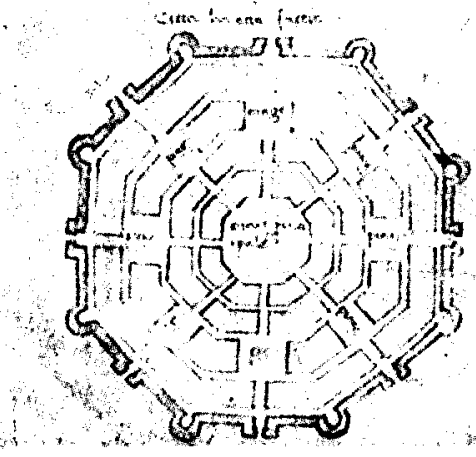

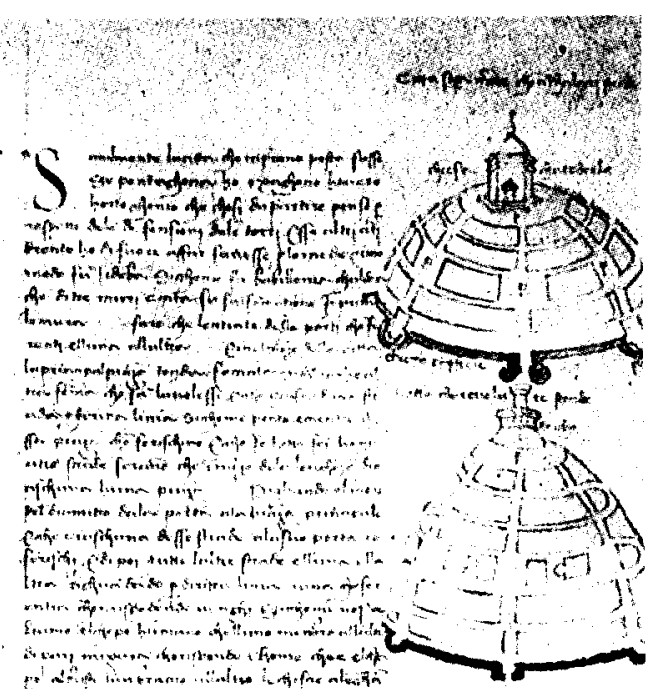

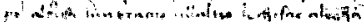

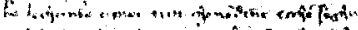

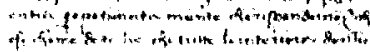

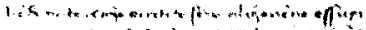

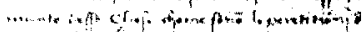

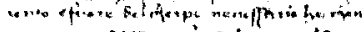

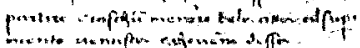

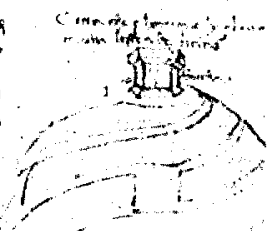

A

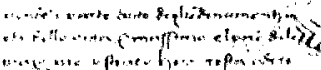

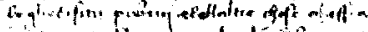

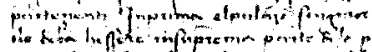

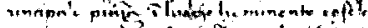

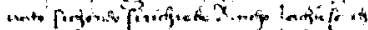

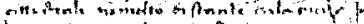

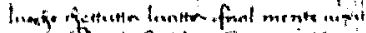

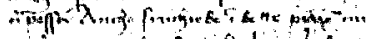

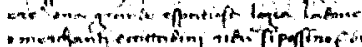

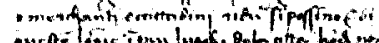

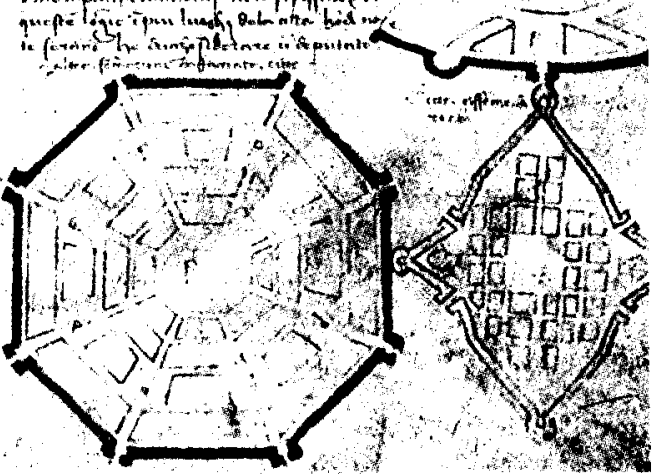

Fig. 1. Plantas de ciudades fortificadas de Francesco di Giorgio Martini. 


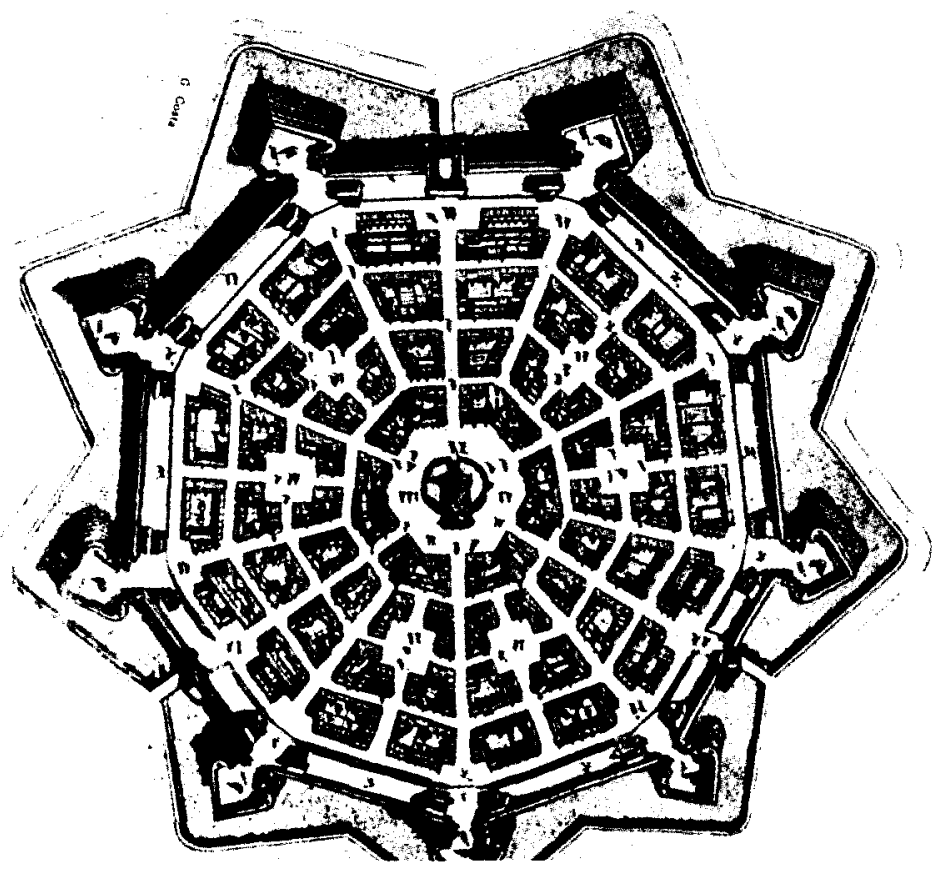

Fig. 2. Planta de la ciudad de Palma Nova (1593), atribuida a Scamozzi.

de postas, ventas; en una de estas seis plazas se colocaría el mercado de ganado.

Alrededor de la ciudad se harían tres calles de árboles, la del medio, más ancha que las laterales, se destinaria al tránsito de carruajes. Más allá de las calles se plantarian los arrabales, dividiendo éstos en cuarteles y reuniéndolos según sus clases: los unos comprenderán los mataderos, lavaderos, fábricas de curtidos, etc.; otros comprenderán los oficios mecánicos que causen ruidos y mal olor, como las fraguas o las fábricas de velas. Un cuartel separado estará ocupado por aquellos oficios cuyo agente principal es el fuego, como tahonas, hornos, carbonerías, etcétera. Otros se destinarán al paseo y recreo de sus habitantes. Habrá que tener en cuenta a la hora de planificar los diferentes cuarteles el sitio que más se adapte a sus necesidades, asi los mataderos, lavaderos y fábricas de curtidos estarán inmediatos al rio. 


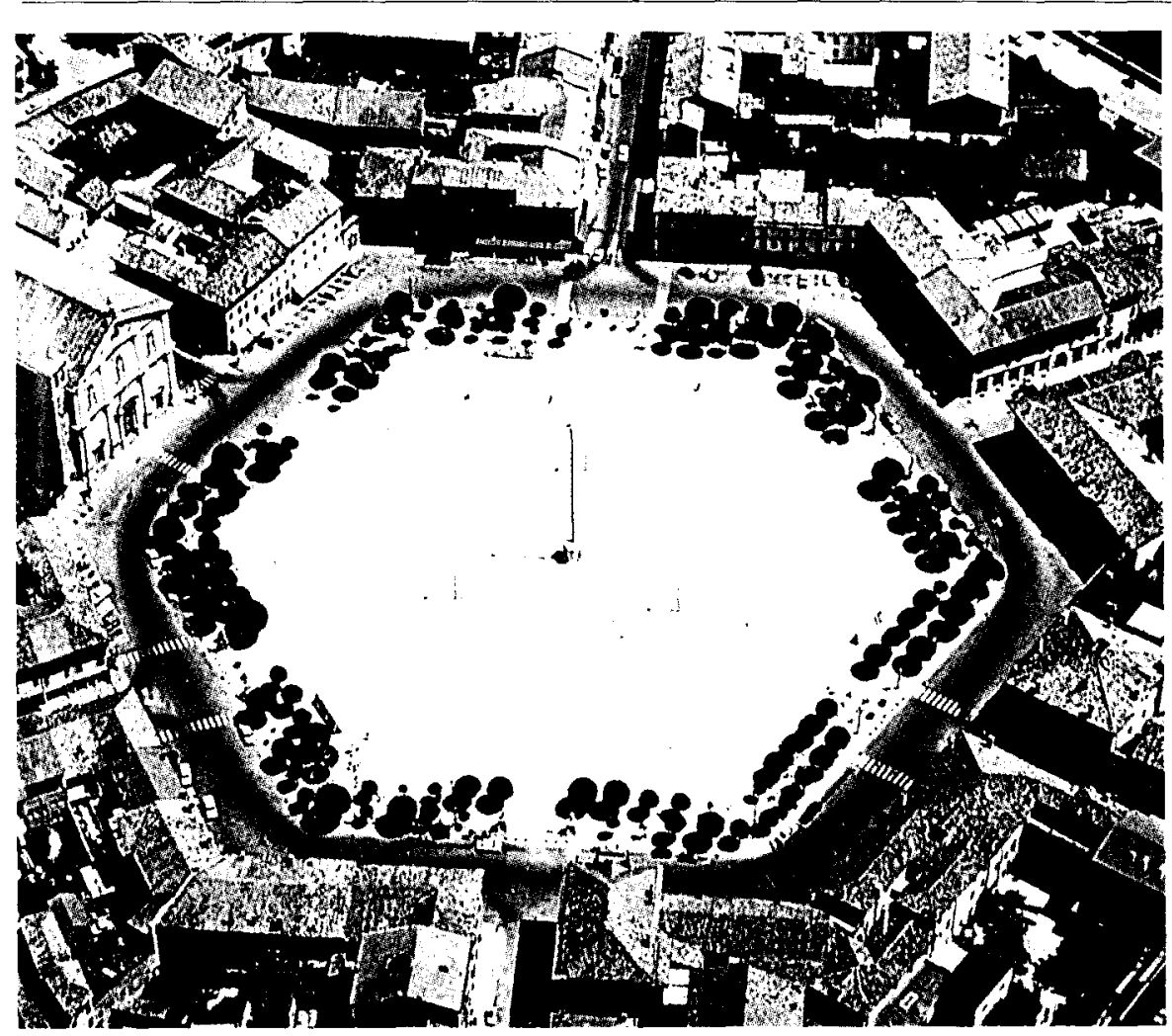

Fig. 3. Contorno hexagonal en la plaza central de Palma Nova.

También en la proximidad de las aguas estarán los baños, pero éstos serán totalmente independientes de aquéllos por medio de un canal que les suministre el agua que necesiten y que vuelve a desaguar al río. Un canal de 30 pies de ancho por lo menos atravesará los arrabales y se comunicará con el río, tanto a su entrada como a su salida de la ciudad; de esta forma se renovará el aire en las cercanías y en el centro. Para la limpieza de las alcantarillas se situarán en el borde de este canal diferentes depósitos de agua, de donde por medio de una máquina hidráulica se elevará y conducirá a los acueductos que han de servir para la limpieza de la ciudad. La idea general está tomada casi al pie de la letra del tratado de Benito Bails; sin embargo, Cano hace precisiones para adaptar la teoría a la práctica.

El sitio destinado a los paseos ofrecerá gran variedad de objetos, bien naturales o creados por el arte. Se harán varias calles de árboles para que sirvan de paseo en verano, y se creará un salón espacioso 
para el invierno. En uno y otro lugar se colocarán a proporcionada distancia asientos dobles de piedra con respaldo de hierro. El paseo se adornará con fuentes graciosas que servirán para el riego, a la vez que refrescarán la atmósfera. También en el paseo se establecerán una fonda y un café con gran pórtico donde pueda recogerse el público en tiempo de lluvia. Una calle separada de las demás se destinará para el paseo a caballo o en carruaje. Así estará reunido todo lo que pueda contribuir a hacer agradable el lugar y que sea útil, como las fondas y los jardines.

De entre los cuarteles de los arrabales, los que deben estar más próximos son los destinados a los oficios mecánicos y de los que se hace un uso cotidiano. Los arrabales se comunicarán por calles de árboles que dividan el terreno en varias figuras y con sembrados de diferentes vegetales a fin de que ofrezcan un aspecto de variedad. La idea que plantea Cano con esta distribución de los arrabales que une por medio de calles con árboles y vegetación es la misma que ya expusiera Laugier en Essai sur l'architecture ${ }^{7}$, la ciudad y sus alrededores tratada como un parque en el que conjugan la geometría y la variedad.

A un cuarto de legua de la ciudad se construirán los cementerios en sitios bien ventilados, donde no causen perjuicios. Es mejor que sean varios en lugar de uno más grande, ya que de esa manera se disiparán con más facilitad los vapores peligrosos. Los cementerios estarán cercados por murallas de 20 pies de altura, alrededor de las cuales se construirán nichos y en medio se construirá una capilla. Se prohibirá el entierro en la ciudad, excepto a los clérigos, frailes y monjas "a quienes no queda nada después de su muerte del olor de santidad que disfrutaban en vida". Añade Cano algunos comentarios sobre el privilegio de enterrar en los templos que la iglesia ya no tiene interés en mantener. En Mémoires sur les objets les plus importants de l'architecture, P. Patte habia recomendado desplazar a los suburbios los oficios que producian ruidos y malos olores; los cementerios y hospitales estarian aún más alejados ${ }^{8}$. El modelo de cementerio que Melchor Cano describe responde al diseño que hizo Juan de Villanueva en 1804 para el cementerio

7 M. A. Laugier, Essai sur l'architecture. Paris, 1755, pág. 222 y sigs., citado por PAOLO SiCA, Historia del urbanismo. El siglo XVIII. Madrid, 1982, págs. 274 y 275.

${ }^{8}$ P. PATTE, Mémoires sur les objets les plus importants de l'architecture. París, 1769. “Más allá de estas filas de árboles (de los boulevards exteriores de las ciudades) se construirán los suburbios, a los que se desplazarán todos los oficios rudos y las artes que originan muchos ruidos y desperdicios (...) y más allá de los suburbios se establecerán, en lugares elevados y bien aireados, los cementerios y hospitales; porque la corrupción que sale de estos lugares infecta el aire y las aguas". Citado por P. SiCA, obra citada, pág. 276. 
del norte de Madrid y que sería imitado en toda España hasta la implantación del tipo de "parque fúnebre» al estilo francés, de gusto ya romántico $^{9}$.

También ocupará las afueras de la ciudad un hospital destinado al tratamiento de las enfermedades contagiosas, procurando que el lugar sea elevado y muy ventilado.

En el caso de que la ciudad deba albergar tropas, aunque no sea una plaza fuerte, se haría un cuartel para su alojamiento en uno de los arrabales próximo al río. El edificio sería proporcionado en dimensiones al número de soldados que deba albergar; para ello se edificarán pabellones separados para oficiales y tropa, con espaciosas galerías que sirvan de comunicación junto con las escaleras que unan unos pisos con otros; el cuartel deberá tener dependencias destinadas a depósitos, cocinas y almacenes, además de espacios, lo mismo cubiertos que al aire libre, para la instrucción de los soldados.

Como resumen, Cano trata de que la ciudad esté rodeada de edificios mezclados entre jardines y huertas, que se descubran en perspectivas a través de los árboles de las diferentes calles de comunicación. Considera que este sistema es el que ha hecho hermosos los alrededores de ciudades como Roma, Atenas y Palmyra; una disposición semejante existe en los Campos Elíseos del Reino de Nápoles. No considera que los monumentos que sirvan de adorno sean tan enormes como las pirámides o los sepulcros de Adriano o de Augusto; en Atenas están el de Temístocles o el de Epaminondas, de una gran sencillez. Este recuerdo del mundo antiguo está copiado textualmente del libro de J. N. L. Durand, Précis de leçons d'Architecture, publicado en $1817^{10}$.

El discurso continúa con la descripción del puente sobre el río que serviria de comunicación con las demás ciudades. El puente tendrá una calzada ancha para el paso de carruajes y andenes para la gentes de a pie. Sus arcos serán rebajados, forma más conveniente porque proporciona al agua un paso más libre. Aquí vuelve a recurrir al texto de Durand al recomendar los arcos escarzanos para este fin ${ }^{11}$.

Los arrabales, atravesados por calles, desembocarán en la ciudad, cuyas puertas se distinguirán por la magnificencia de su decoración. En

${ }^{9}$ Sobre el tipo de cementerio español ver el artículo de CARLOS SAGUaR QUER, «EI cementerio General del Norte de Madrid", Goya, n. ${ }^{\circ}$ 196, pág. 213 y sigs.

${ }_{10} \mathrm{~J}$. N. L. DuRAnd, Précis de leçons d'Architecture donnés a l'Ecole Polytechnique (1817). Ed. castellana Pronaos, 1981, pág. 120, trata de los accesos de las ciudades.

$"$ J. N. L. DuRAnd, obra citada, vol. 2. ${ }^{\circ}$ pág. 122. 
este párrafo Cano recuerda los arcos triunfales romanos que se construyeron para «transmitir a la posteridad la memoria de sus victorias» y cuyo ejemplo han seguido todas las naciones de Europa. Además de hacer memoria de los diferentes arcos romanos que han quedado (Ancona, Benevento y los de Constantino y Septimio Severo, en Roma), opina que una disposición semejante a la de los arcos romanos puede aplicarse a las entradas de las ciudades. Por ello se harán tres entradas triunfales correspondiendo a las tres puertas principales y otras tres mucho más sencillas que corresponderian a los portillos; en éstas bastaría un arco de medio punto en el centro y dos huecos cuadrados a los lados. El planteamiento de arco triunfal como acceso a la ciudad es semejante al descrito por Milizia quien también detalla los arcos antiguos romanos. Una exposición análoga hace Durand en Précis de leçons... ${ }^{12}$.

\section{LAS CALLES Y PLAZAS}

Una vez que ha descrito cómo debe ser el contorno de la población y sus alrededores, Cano continúa con el trazado de las calles. De las tres puertas principales tres calles se dirigirán al centro de la ciudad, donde se formará una gran plaza de figura hexagonal, pero de tal modo que sus desembocaduras estén enfrente de los lados que no se hallan divididos por ninguna calle.

La plaza servirá para escenario de las fiestas y estará rodeada de pórticos espaciosos. En uno de los lados estará la Casa Consistorial con sus dependencias (sala de juntas, cuerpo de guardia con cárcel, etc.). En el otro lado estará la iglesia matriz y en el tercero el teatro. Las casas de la plaza se destinarán a los jefes políticos y militares. También se situará en la plaza la Audiencia con sus salas y oficinas, una Academia de Bellas Artes y una Universidad con su biblioteca.

En el centro de la plaza se situará un monumento a la memoria del fundador de la ciudad. Grandes arcos cerrarán las desembocaduras de las calles y los pórticos espaciosos proporcionarán un paseo cómodo defendido "contra las injurias del tiempo". Algunas fuentes esparcidas por la plaza proporcionarán frescura al ambiente. Todos estos elementos

12 F. Milızıa, Principi di Architettura Civile, 1781, págs. 47 y 409 . J. N. L. Durand, obra citada, págs. 129-121. 
darán lugar a una plaza "digna en todo de rivalizar con las construidas por griegos y romanos" (fig. 4). La disposición de esta plaza no será de la aprobación de los favoritos de las plazas eurítmicas de aquellos que quieren que las plazas estén rodeadas de un solo edificio, o de los que hacen una plaza para que luzca uno ostentoso. Esta rigurosa euritmia no fue observada por los antiguos.

Comenta Cano a continuación que entre las plazas antiguas destaca la de Halicarnaso, construida por Mausoleo sobre un terreno en pendiente que se prolonga hasta el mar; el magnífico foro o mercado de Trajano, que según la relación que hace Pausanias tenia edificios admirables como una basílica, un templo, una biblioteca, arcos triunfales, magníficas fuentes, además de la columna que se levantó después de la victoria de Trajano sobre los daceos.

Entre las plazas modernas, cita la plaza Vêndome, en Paris, hecha durante el reinado de Luis XIV, con planta de paralelogramo, con ángulos achaflanados, rodeada de casas particulares; excepto en sus entradas la decoración es uniforme, con un orden corintio apilastrado, construido sobre un basamento, cuya altura es los dos tercios del orden. En el centro se halla la estatua del monarca. La referencia a esta plaza francesa parece una cita obligada, quizá nunca la vio Cano pero su conocimiento le pudo venir por la descripción que hace Laugier en Observations sur l'Architecture, y los comentarios de Antonio Ponz en su Viaje fuera de España ${ }^{13}$.

Cano considera las plazas modernas áridas a pesar de su simetría, lo que no sucede con la descripción de las plazas antiguas. La diferencia entre unas y otras está en que en las modernas no se trata más que de la decoración, mientras que en las antiguas el interés está en la disposición de los objetos ${ }^{14}$. Si debe haber determinados edificios públicos, es aconsejable que éstos estén en el centro de la ciudad, reunidos, $y$ "satisfagan de este modo a la comodidad, economia y ornato".

Al planear la ciudad para seis mil vecinos considera que debe dividirse en seis cuarteles; en cada uno de ellos habrá tres plazas, una para la venta de comestibles y las otras dos para desahogo del vecindario; en una de ellas, en el centro de cada distrito, se situará la iglesia parroquial.

13 Observations sur /'Architecture par M. L'ABBE LAUGIER, La Haye, 1765, pág. 195. Antonio Ponz, Viaje fuera de España, 1785. Vol. I, ed. Aguilar, 1989, pág. 112.

14 Esta diferenciación entre la concepción de las plazas de antiguos y modernos, aunque ya se había tratado con anterioridad, está literalmente tomado, incluso con los ejemplos del libro de Durand, ya citado, págs. 122-124. 
$L I$ If $R$ O T E I $Z O$.

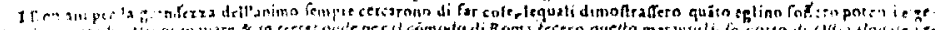

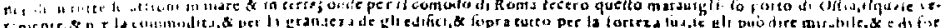

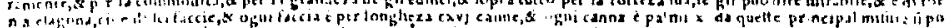

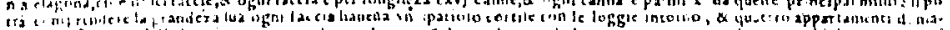

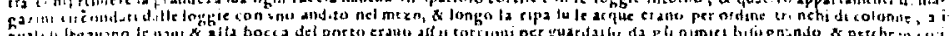

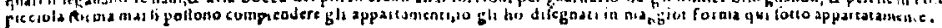

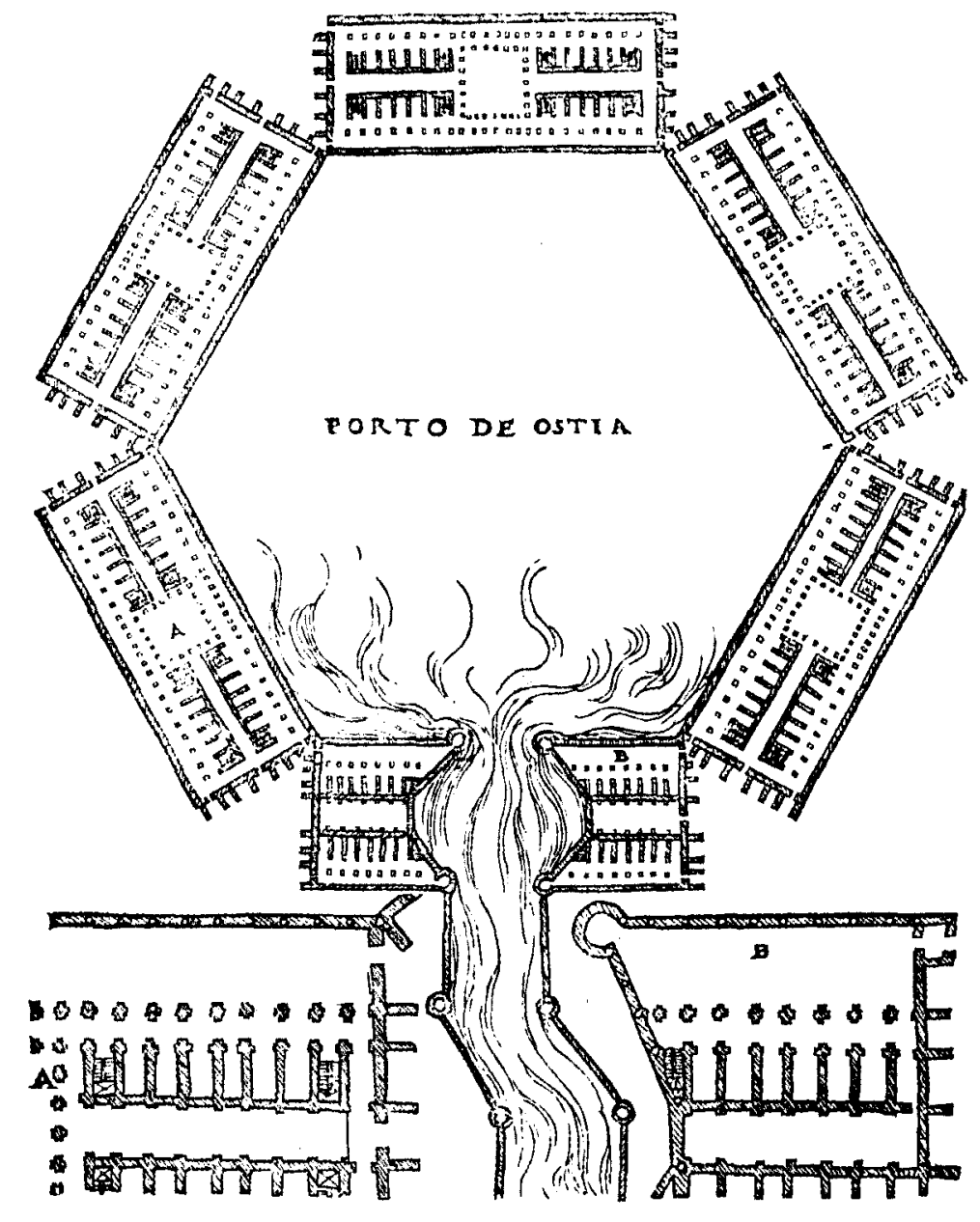

Fig. 4. Diseño de la planta del puerto de Ostia. Tutte l'opera D'Architettura et prospetiva di Sebastian Serlio, 1600, Libro tercero. 
Estas iglesias serán variadas, cada una debe tener algo particular que llame la atención de los curiosos. Además de diferentes consideraciones sobre las dependencias con que debe contar el templo, Cano señala que el edificio tiene que estar aislado, con calles anchas alrededor y una plaza al frente ${ }^{15}$.

En cada una de las plazas se situará un hospital para los vecinos pobres de cada distrito de parroquia. Será un hospital pequeño, ya que fuera de la ciudad se establecerá otro para los enfermos contagiosos. Estos hospitales destacarán por su salubridad, contarán con pabellones separados para ambos sexos y espaciosos pórticos. También en las plazas se situarán las escuelas de primera enseñanza, doce en total, que ocuparán edificios independientes. Cano alaba en lo referente a las escuelas el modelo inglés, con edificios construidos para tal fin que cuentan con patios al aire libre, pórticos y jardines.

La ciudad también deberá contar con una casa de beneficencia situada en una de las plazas, para evitar que los mendigos posean la ciudad. En esta institución se preparará a los mendigos en el trabajo y en la moral; contarán con talleres y almacenes para que puedan realizar tareas con las que ayudar al mantenimiento de la casa.

En cada una de las doce plazas se situarán casas de vecindad, procurando que todas tengan una misma altura y decoración exterior, disponiéndolas de manera que resulte simetría de su situación. Estas plazas, que deben servir de desahogo al vecindario, estarán divididas por varias calles de árboles, tendrán asientos de piedra y una fuente en el centro para el riego y el servicio del vecindario.

Además de los edificios públicos ya mencionados, será conveniente establecer otros menos conocidos. Uno será un Archivo General de la Propiedad donde los escribanos llevarian los expedientes y donde se archivarían los títulos de propiedad de los vecinos de la ciudad. El edificio estará en una de las calles principales, aislado y construido de un modo incombustible.

Otro tipo de edificio necesario en la ciudad estará destinado a evitar "que las calles se hallen infectadas de excrementos". Estos evacuatorios se construirán en diversas encrucijadas, lugares comunes donde los transeúntes hagan sus necesidades, con depósitos de agua que aseguren la

15 La descripción de estas iglesias parroquiales y su ubicación está tomada de BAILS, obra citada, pág. 809, que a su vez la había adquirido del libro de LaugIER, Essai sur l'architectura, Paris, 1755, pág. 206. 
limpieza. Este tipo de construcciones, según Melchor Cano, eran cosa común en las ciudades de Europa.

En el centro del distrito de cada cuartel habrá una plaza para la venta de comestibles. Entre los antiguos, los mercados eran plazas públicas como la de Augusto o Trajano, siempre en lugares extensos, ventilados, plantados de árboles y rodeados de pórticos, con fuentes para proporcionar frescura y limpieza. Todo lo contrario sucede en los mercados de la actualidad.

En la nueva ciudad se formará un recinto de casas particulares, sujetas a una misma decoración y altura. En ellas se colocarán las carnicerías, la alhóndiga y los grandes almacenes para depositar los géneros del mercado. Un lugar separado se destinará al pescado, las verduras, las flores, los animales de toda especie y toda clase de comestibles que desprendan olores y deban estar aireados. Las legumbres, vinos, cereales, telas y otros productos que puedan alterarse con el aire, el sol o las lluvias, se venderán siempre en sitio cubierto, en los pórticos o almacenes ${ }^{16}$. En cada plaza habrá un regidor de policia que vigile la buena calidad de los comestibles y cuide de la tranquilidad pública. Estas plazas estarán divididas por varias filas de árboles que marcarán los diferentes lugares para los vendedores y los defenderán del sol.

\section{LA DISTRIBUCIÓN INTERIOR}

Para que la ciudad proyectada sea bella, razona Cano en su discurso, no es necesario que tenga una exacta simetría, como en las ciudades de Japón o China, ni que "sea una reunión de cuadrados o paralelogramos", to esencial para la distribución de sus calles es que todas sus avenidas sean fáciies, que haya suficientes pasos de un cuartel a otro y que sus extremos puedan comunicarse del centro a la circunferencia sin cofunsión; es preciso evitar la monotonia o la uniformidad en la disposición total de su plano para que brille la variedad y la contraposición de las formas, para que unos cuarteles no se parezcan a otros. "El viajero no debe descubrirlo todo a un golpe de vista, es necesario que sin cesar sea atraído por espectáculos interesantes, por una agradable combina-

${ }^{16}$ La idea de un mercado perfectamente distribuido según su destino está tomada al pie de la letra del texto de Durand, ya citado, págs. 136-137. 
ción de plazas, edificios públicos y casas particulares". Todo lo expuesto por Melchor Cano nos retrotrae de nuevo a la Arquitectura civil, de Benito Bails, quien a su vez bebe en fuentes anteriores, Milizia sobre todo, aunque el concepto de variedad, unido al de articulación de las partes, habia sido suficientemente explicado por P. Patte en Mémoires sur les objets les plus importants de l'architecture (1769) a partir de las ideas vertidas anteriormente por Laugier ${ }^{17}$.

El ancho de las calles y la elevación de las casas depende del clima en que se construya la ciudad; en los países fríos y templados conviene hacerlas más anchas y espaciosas que en los paises calientes. La anchura hace que el sol penetre, caliente las casas y disipe la humedad. Además las calles anchas son despejadas para el tránsito y descubren la grandiosidad de los edificios. Lo contrario es aconsejable en los climas cálidos, la menor anchura de las calles contribuye a crear sombras y luchar contra el calor. Así, en los países templados las calles deben tener de 42 a 70 pies de ancho, estar bien alineadas, sin obstáculos en su alineación y con edificios de tres pisos ${ }^{18}$.

Las fuentes serán un ornato para la ciudad, le darán un aire de vida y contribuirán a su limpieza; además de colocarse en las plazas, se instalarán otras en las calles en forma de entrantes para que no perjudiquen la alineación de las calles. Sus aguas irán a las alcantarillas y servirán para la limpieza.

Para adornar la ciudad será necesario que cada edificio sea tratado según el destino que tenga, a imitación de las antiguas ciudades griegas. Las fachadas de las casas deben ser regulares y variadas, huyendo siempre de seguir una misma decoración en las de una misma calle, lo que haría que pareciesen un mismo edificio; el acierto depende de las diversas formas que se den a los edificios, de la variación de sus adornos y del modo diferente en que se combinen unos con otros. Las casas particulares serán de arquitectura sencilla, reservando la riqueza de la arquitectura para los edificios públicos, aunque no a todos se les hará

${ }_{17}$ F. MllızıA, Principi di Architettura Civile, 1781, part. 2, pág. 44. Similar planteamiento aparece en el texto de LAUGIER, Essai sur l'architecture. "... Diseñar el plano de una ciudad de manera que la magnificencia del conjunto se subdivida en infinidad de bellezas de detalle, todas ellas diferentes, de modo que el viandante no vuelva a encontrar casi nunca los mismos objetos, que al recorrer la ciudad de un extremo a otro sea posible descubrir en cada barrio algo nuevo, singular y atrayente; que exista un orden $y$, sin embargo, que se dé una especie de confusión".

${ }^{18}$ El párrafo está sacado casi literalmente de B. Balls, obra citada, pág. 25 , quien a su vez lo expone como tomado de PATTE, Mémoires d'Architecture, pág. 13. 
igual: "Las masas que forman el edificio acomodadas a su carácter son las que deciden el ornato que les corresponde, como partes esenciales e integrantes suyas, y cuyo ornato es la expresión que mejor indica su destino". De esta manera se hará en los edificios de la plaza principal, en los que se verá la importancia y destino de cada uno de ellos.

Para la comodidad de los habitantes no se harán pórticos ni pretiles en las calles, éstas sólo estarán divididas en tres partes, separadas por dos arroyos que formarán la unión de las vertientes de la del medio con las de sus lados; el centro se destinará a los carruajes y los laterales para los de a pie. En calles de 42 pies se destinarán 25 a la parte central y 8 ó 9 para las laterales. En las calles principales se destinarán 12 pies para el paso del público y lo restante para los carruajes. Para evitar las encrucijadas se redondearán los ángulos que forman las esquinas de las calles.

Las casas no deben ser elevadas, a lo sumo tres pisos terminados en azotea con balaustrada o bien con tejado plano a lo largo de la facha$\mathrm{da}$, sin canalones ni vertederos. En los paises septentrionales es aconsejable que los tejados sean muy pendientes para que no se detenga en ellos la nieve, norma que no se sigue, pues en Francia son habituales los tejados a la mansarda.

Las aguas de lluvia se recogen en bajadas hasta las alcantarillas que comuniquen con la general, asi se evitarán las inundaciones.

\section{LA SALUBRIDAD DE LA POBLACIÓN}

La última parte del discurso está dedicada a exponer una serie de ideas sobre salubridad y limpieza de la población.

Una necesidad en la ciudad es un empedrado de las calles adecuado. En la antigua Roma y en sus caminos militares se hacia un empedrado con piezas de cerca de 20 pulgadas en cuadro, sentadas sobre un macizo de ladrillos de tres pies de grueso. Éste es el sistema seguido en las calles de Nápoles, Florencia y Constantinopla. Las calles de Madrid están empedradas de morillo de cuñas o paralelepípedos de pedernal, piedras sentadas sobre una base de arena apisonada, pero muy deteriorada por el paso de carruajes. El mejor empedrado es el que se usa en Paris, consiste en piedras de siete a ocho pulgadas en cuadrc. Los pasos laterales deben hacerse de losas todas del mismo tamaño que se asien- 
tan sobre un buen cimiento, de esta forma además de contribuir a la comodidad de los peatones se protegen los edificios al resguardarlos de la humedad.

La limpieza de la ciudad es uno de sus principales ornatos: «De nada sirve levantar lujosos edificios, si proliferan los malos olores". Cano opina que, independientemente del río que discurre de oriente a poniente de la ciudad, se debía hacer entre ella y los arrabales un canal de circunvalación con "reservatorios" de donde se sacaría el agua necesaria para distribuir en los diferentes cuarteles de la ciudad. El sistema es de los antiguos romanos, no hay más que practicar en todas las calles acueductos subterráneos capaces no sólo de servir al transporte de las inmundicias, sino también de asegurar la solidez de los conductos y favorecer su conservación. Las alcantarillas están formadas por arcos de dovelas en piedra que llegan a un acueducto general y luego desaguan en el río fuera de la ciudad. Caños de hierro conducirán las aguas del río o de manantiales a las casas, fuentes y jardines.

Se harán pozos para depositar las basuras de las calles, en los que los barrenderos arrojen los desperdicios, con tapas que se levantarán al arrojar las basuras al acueducto subterráneo junto con el agua que se ha ido acumulando en los depósitos durante la noche.

El discurso termina con la idea de que un arquitecto encargado de formar una ciudad debe reunir, además de sus conocimientos artísticos, alguna filosofía para discurrir sobre las necesidades de una población numerosa: "Combinará las reglas de arquitectura con las demás circunstancias que necesita una reunión de edificios destinados para diferentes objetos y para vivienda de una multitud de habitantes».

\section{LAS FUENTES DEL DISCURSO}

Aunque nos encontramos ante un texto forzosamente erudito -es un discurso académico-, en él encontramos una perfecta combinación de fuentes literarias (sobre todo tratados de arquitectura), recuerdos arqueológicos y observaciones prácticas sacadas del aprendizaje del oficio.

La razón de esta combinación de elementos tendríamos que buscarla en la formación académica de Melchor Cano y su aprendizaje forzosamente condicionado por los planes de estudio. 
Como cualquier otro estudiante de la Academia de San Fernando en el ramo de la arquitectura, estaba familiarizado con las traducciones que José Ortiz y Sanz había hecho en 1787 de Los diez libros de Arquitectura de M. Vitruvio Polión, y en 1797 de Los cuatro libros de Arquitectura de Andrea Palladio. Estos textos, al igual que los de los grandes tratadistas de Italia León Battista Alberti, Serlio o Vignola, estaban disponibles para su estudio en la biblioteca de la Academia ${ }^{19}$.

Es escaso el conocimiento de textos franceses, aunque a lo largo de la exposición del discurso hayamos señalado algunas de las ideas de Cano como asimiladas de la obra de Laugier, "Essai sur l'architecture (1755), o de la de P. Patte, Mémoires sur les objets les plus importants de l'arquitecture (1769); decimos escaso porque hay una fuente más próxima que Cano sin duda utilizó, el libro de Benito Bails, De la arquitectura civil, publicado por primera vez en 1783 y reeditado varias veces con un carácter de cartilla de arquitectura para los aprendices del oficio. Este libro fue ampliamente manejado por los alumnos de la Academia, dada la condición de profesor de Bails, hasta fecha bastante avanzada. Así, puede también explicarse el conocimiento de los Principi di Architecture (1781) de Francesco Milizia, obra saqueada por Bails en su texto y combinada con las de los teóricos franceses ya mencionados ${ }^{20}$.

Llama la atención en el texto de Cano las aportaciones directamente tomadas del libro de Durand, Précis de leçons, que hemos citado en varias ocasiones. Sin embargo es una contribución limitada, tan sólo toma de Durand las citas arqueológicas y algún concepto general, pero, en suma, su planteamiento no es tan utilitario como el expuesto en el Précis..., aunque sí puede encontrarse algún contacto en la idea general de conseguir una utilidad pública y privada en la arquitectura: el tratar de diseñar una ciudad en la que la estancia resulte saludable y en la que la belleza resulte de la mezcla de objetos variados y no de la simple decoración.

El interés por la arqueología es otra constante a lo largo del discurso, el considerar a las antiguas Grecia y Roma como ideal de vida y de arte, el mundo perdido para los individuos del siglo XIX, que tratan de recuperar con el conocimiento de sus ruinas. Los estudiantes de la Academia podía consultar la traducción de la obra de Richard Wood, Les ruines de

19 Sobre la formación de los académicos hay que tener en cuenta el libro de ClaUdE BÉdat, La Real Academia de Bellas Artes de San Fernando, 1744-1808. Madrid, 1989.

20 Pedro Navascues trata ampliamente de las fuentes De la Arquitectura..., de Balls, en el estudio crítico que hace a la edición facsímil de la obra, publicada en Murcia en 1983. 
Palmyra (1753), hecha por Felipe de León en 1768, o The Antiquities of Athens (1762) de Stuart Revett, traducida el mismo año de su publicación por Felipe García Samaniego; todo ello sin olvidar el insustituible texto de Winckelmann, La historia del arte entre los antiguos, cuya traducción fue realizada por Antonio Rejón de Silva y entregada a la Academia en 1797. Todo ello se unía a las continuas referencias a la arquitectura romana que se recogian en el libro de Milizia. Estos textos se juntaban con otros que poseía la biblioteca de la Academia y que permitían conocer los hallazgos de piezas de otras culturas antiguas.

La formación teórica se une al interés por hacer una arquitectura utilitaria que cubra las necesidades de los individuos. Aunque el concepto de ciudad poligonal procede de Vitruvio y de él pasa al Renacimiento hasta llegar a Milizia y Bails, Cano adopta una postura renovadora, una ciudad centralizada, pero al mismo tiempo dividida en cuarteles bien relacionados y articulados como partes de un todo.

Huye también Melchor Cano de la idea de una ciudad simétrica, al gusto ilustrado, que da lugar a un modelo que se repite hasta el infinito: la cuadrícula uniforme, que tanto se utilizó en América y que en España tuvo su gran apogeo, en fechas próximas a las del discurso, en las nuevas poblaciones de Sierra Morena y Andalucía.

El espiritu del discurso es el de conseguir una ciudad en la que se llegue a la belleza por el utilitarismo: estén previstos aspectos como el tránsito, la limpieza, el alcantarillado, la comunicación entre barrios, la salubridad, en fin todo aquello que dé lugar a una ciudad moderna. Como arquitecto del siglo XIX, Cano ha prescindido de la idea de la arquitectura como repetición de modelos ya establecidos, prefiriendo hacer una que se adaptase a las nuevas necesidades de la población. De hecho ésta era una preocupación que la Academia tenia presente y que trataba de introducir en los planes de estudio que puso en marcha en $1821^{21}$.

\section{CANO, ARQUITECTO MAYOR DE SEVILLA}

La llegada a Sevilla de Melchor Cano y su nombramiento como maestro mayor a la muerte del anterior, José Echamoros, en marzo de

21 La formación del arquitecto en España en la primera mitad del siglo Xix ha sido tratada desde las fuentes teóricas en el libro de Julio ARREChEA Miguel, Arquitectura $y$ romanticismo. El pensamiento arquitectónico en la España del XIX. Valladolid, 1989, página 29. En él plantea la insuficiente formación de los arquitectos en la Academia y la necesidad de hacer frente a nuevas demandas. 
1825 , supone la definitiva instauración en la dirección de las obras municipales de un maestro arquitecto y académico, un profesional formado en la Academia de Madrid y alejado de los anteriores maestros de obras educados en la práctica constructiva.

El 18 de septiembre de 1827, don José Manuel de Arjona es nombrado presidente de la Junta Rectora de la Academia de Bellas Artes de Santa Isabel de Sevilla; con ello se cumplía la Real Orden del 17 de abril de 1827, por la que según el Reglamento de la Real Academia correspondia al asistente de Sevilla la dirección y gobierno de la Real Escuela ${ }^{22}$. Para que comprendamos la relación existente entre Arjona y Melchor Cano, nada mejor que observar que el 23 de octubre de 1827 éste es nombrado director de Geometría Práctica y Perspectiva de la Academia de Nobles Artes. Su vinculación con la institución continuará hasta su muerte. El 15 de marzo de 1829 es nombrado director de Arquitectura a la muerte de Fernando Rosales que antes ocupaba este puesto $^{23}$.

La labor de Cano en Sevilla no se circunscribirá al Ayuntamiento, sino que también fue arquitecto del Real Consulado, del Cabildo Eclesiástico y director de las obras del Real Patrimonio. Su trabajo adquiere asi una gran amplitud: vigilancia de los proyectos urbanos, acometida de obras de saneamiento de la ciudad y la atención a la conservación y restauración del patrimonio antiguo, la catedral y los Reales Alcázares.

Como hemos podido ir viendo en la exposición que se hace en su discurso, su concepto de ciudad está perfectamente consolidado: no sólo se ha ocupado de los aspectos formales o arquitectónicos, sino que muestra interés por los problemas de policía urbana, de gobierno de la ciudad. Una prueba de este interés es el Reglamento de Policía Urbana que presenta al asistente Arjona en septiembre de 1828. El texto se enuncia de la siguiente manera: "Instrucción que se ha de observar por los empleados del ramo de Policía Urbana. Para el mejor ornato y aspecto público, seguridad, salubridad, aseo y limpieza de las calles de esta ciudad» 24 .

El Reglamento, de cinco artículos, señala las normas que se deben seguir en la ciudad a la hora de edificar, la prohibición expresa de labrar

\footnotetext{
22 Antonio Muro Orejon, Apuntes para la historia de la Academia de Bellas Artes de Sevilla. Sevilla, 1961, pág. 41.

23 A. Muro Orejon, obra citada, pág. $14 \dot{9}$.

${ }^{24}$ Archivo Municipal de Sevilla, sección $6 .^{a}$, tomo 116 . Reglamento fechado el 20 de octubre de 1828.
} 
sin obtener la oportuna licencia del Ayuntamiento para lo que habría de presentarse un plano de la obra a realizar. Igual solicitud debe cursarse para hacer cualquier modificación en las fachadas, todo ello para conseguir el mejor ornato y aspecto público. Hay en el Reglamento una especial atención a la conservación del pavimento, saca de escombros, conservación del alumbrado, jardines y sobre todo la limpieza de las calles y lugares públicos. Destacan aspectos curiosos como la prohibición de tener cerdos en las casas de la ciudad o de regar durante el día durante el día los tiestos de ventanas y azoteas.

Todas las normas señaladas y la vigilancia de su cumplimiento estaba encomendada a un visitador general de Policía Urbana y a dos celadores por cada cuartel. Un escribano llevaría registro de las multas impuestas por la falta a estas normas.

El Reglamento supone la confirmación de una normativa fija y moderna para el funcionamiento de la ciudad y la vigilancia de los diferentes servicios. De hecho este Reglamento se amplió a través de un edicto el 11 de mayo de 1829 y otro de abril de 1830 , que estarán vigentes hasta mediados de siglo ${ }^{25}$.

\section{LAS INTERVENCIÓN URBANA}

La serie de obras que se llevan a cabo en Sevilla por la intervención de Melchor Cano se debe mucho a la iniciativa del asistente Arjona, pero es en realidad la colaboración entre ambos personajes lo que va a posibilitarlas. El discurso académico que hemos descrito anteriormente, muestra cómo Cano, antes de su llegada a Sevilla, poseia un concepto propio de lo que debe ser una ciudad. Hay notables diferencias respecto al discurso; lo que va a encontrar no es una población a diseñar, sino una ya trazada pero necesitada de profundas transformaciones. Por ello la colaboración entre Arjona como soporte oficial y Cano como arquitecto diseñador va a configurar una nueva Sevilla más acorde con la imagen emblemática que se desea que represente.

Una labor importante que se acomete durante el gobierno Arjona es la regulación del abastecimiento de agua a Sevilla con la construcción de

${ }^{25}$ Alfonso Braojos Garrido, Don José Manuel de Arjona, asistente de Sevilla (18251833). Sevilla, 1976, pág. 306. 
un nuevo acueducto desde los caños de Carmona ${ }^{26}$. También se modernizó el alumbrado, que incluyó el barrio de Triana, al otro lado del río Guadalquivir; Melchor Cano tuvo que realizar un exhaustivo padrón de sus casas para asi poder exigir el arbitrio de alumbrado. La iluminación estuvo concluida en noviembre de $1827^{27}$.

La tarea de mejora de la fisonomía urbana se continuó con las operaciones de empedrado y embaldosado de calles, así como la eliminación de edificios ruinosos y soportales que entorpecian la vista de las calles sevillanas, de por si estrechas.

Desde 1827 a 1833 se inauguraron varios cementerios en Sevilla, tres próximos a las murallas y un cuarto al otro lado del río, en Triana. El mismo Cano hizo los diseños del de San Sebastián (1830); en la planta sigue el modelo que había expuesto en el discurso, lo mismo puede decirse de crear varios cementerios pequeños en lugar de uno grande ${ }^{28}$.

Alfonso Braojos, en su libro dedicado al estudio del gobierno de Arjona, resalta la tendencia que hay en estos años a restringir la venta de alimentos fuera de los recintos acotados para este fin. Las plazas de la Encarnación, el mercado de Triana y el de Feria asumirán el papel de recintos para la venta de alimentos. Melchor Cano proyectó la plaza de la Encarnación (1832), solar resultante del derribo del convento del mismo nombre realizado durante el reinado de José Bonaparte; en ella vigiló la uniformidad de las fachadas que daban a la plaza y delineó la distribución, todo ello bajo la resolución favorable de la Academia ${ }^{29}$. Como podemos ver, este interés por delimitar el destino de las plazas ya estaba reflejado en el discurso (fig. 5).

Melchor Cano diseñó la plaza del Duque de Victoria, situada en una zona céntrica de la ciudad, como salón o jardín para el paseo. La parte central era en forma de salón, con cuatro calles formadas por filas de árboles. Estaba adornada con vistosos faroles y una fuente coronada por un obelisco centraba el conjunto ${ }^{30}$. La obra, que se terminó en 1828 , es un ejemplo de la aplicación del modelo de plaza para desahogo del vecindario que Cano había propuesto.

${ }^{26}$ Braojos Garrido, obra citada, pág. 264.

${ }^{27}$ Braojos Garrido, obra citada, pág. 299.

${ }^{28} \mathrm{~J}$. M. SuARez Garmendia, Arquitectura y urbanismo en la Sevilla del siglo xix. Sevilla, 1988, pág. 59.

${ }_{29}$ J. M. SuÁRez GaRmendia, obra citada, pág. 49.

30 A. Braojos Garrido, obra citada, pág. 325. 


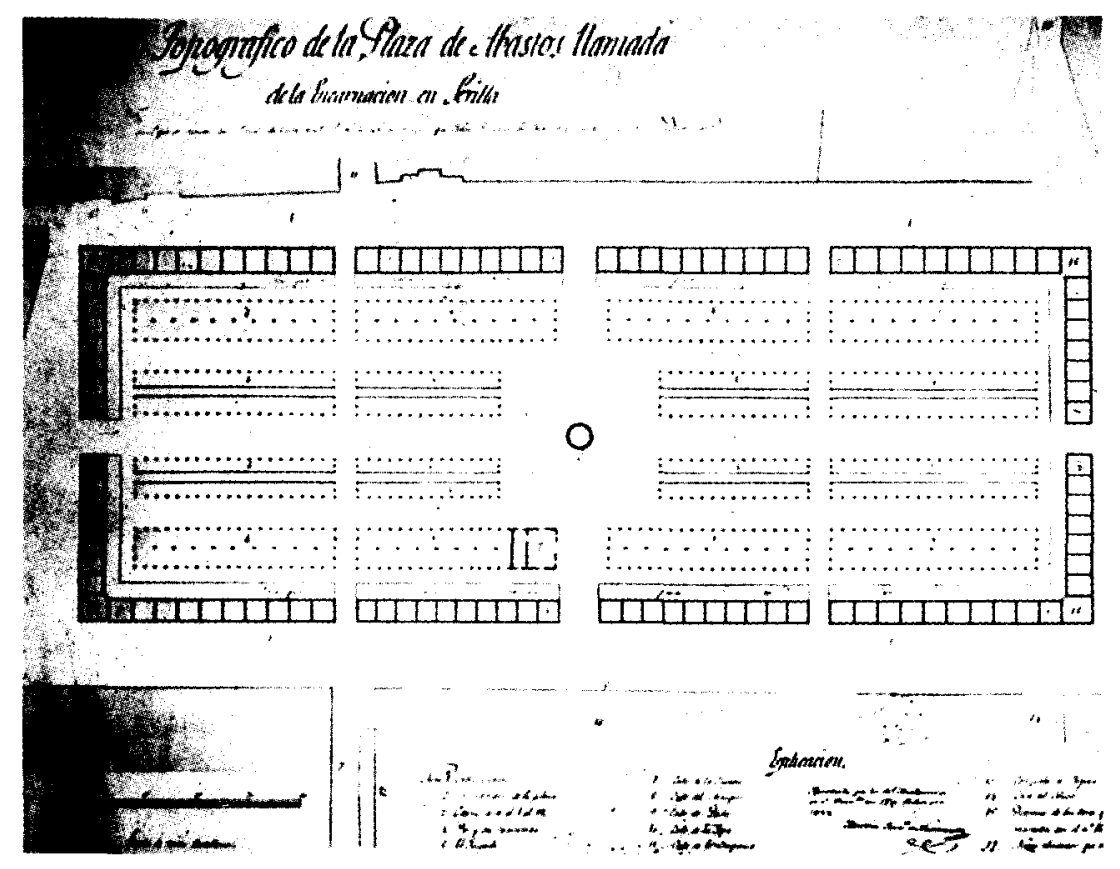

Fig. 5. Melchor Cano: Proyecto de alineación de la plaza de la Encarnación de Sevilla para mercado, 1832.

Pero son sin duda los proyectos para el paseo de las Delicias y el Salón de Cristina, diseñados por Cano, lo más representativo de la intervención del asistente Arjona en Sevilla. Estos jardines estaban en la periferia de la ciudad, fuera de la muralla, y su concepto está perfectamente enlazado con lo expuesto en el discurso que hemos comentado. Por una parte, se han acondicionado los accesos a la ciudad, se ha consolidado la muralla y se restauran las puertas de entrada; por otra, se urbanizan como jardines destinados al ocio zonas periféricas hasta entonces ignoradas $o$ a lo sumo destinadas a huertas. La intención es crear alrededores pintorescos que introduzcan en una ciudad majestuosa ${ }^{31}$.

${ }^{31}$ Antonio Gonzalez Cordón, en Vivienda y ciudad. Sevilla, 1849-1929 (Sevilla, 1985), resalta la importancia que adquieren los alrededores de Sevilla en estos momentos: Las Delicias de Arjona y los Jardines de Cristina forman parte de una serie continuada de intervenciones que registran el territorio no como un "ensanche de la población" sino como un referencia equivalente y culta heredada de la llustración y cuyo significado está en la aprobación burguesa del ocio a través de un nuevo paisaje. 
El paseo de las Delicias, de Arjona, tenía una superficie triangular, entre el paseo de la Bella Flor y el río Guadalquivir. Tenia cuatro hileras de álamos que lo ceñian y se plantó además con especies de árboles exóticos. Para su riego se construyó una bomba que sacaba el agua del río, estaba cubierta por un templete de estilo gótico que le añadia pintoresquismo. Estuvo prácticamente terminado en $1829{ }^{32}$.

El Salón de Cristina se inauguró en 1830 y ocupaba un gran espacio entre la Torre del Oro y el Palacio de San Temo, próximo al Guadalquivir. Su nombre responde al de la esposa del rey Fernando VII. El diseño es semejante al empleado en las Delicias, un salón central y filas de árboles. Como detalle gracioso se construyó un café de estilo chinesco. Se instalaron entre los árboles bancos con asientos de piedra y respaldos de hierro.

Los expuesto refleja el interés por crear un espacio dedicado al paseo, con detalles de pintoresquismo, abundante vegetación y edificios importantes que se divisen entre los árboles, todo ello se mezclaba con huertas y establecimientos útiles alrededor de las entradas de la ciudad.

La obra de Melchor Cano en Sevilla es, como hemos podido ir viendo, la de un arquitecto de transición. Formado aún en la teoría arquitectónica del siglo XVIII, trata de introducir en su ciudad unos conceptos de modernidad: saneamientos, equipamientos necesarios, hospitales, cementerios o edificios representativos como los teatros (no olvidemos que proyectó el ya desaparecido teatro Cómico Principal), todo ello sin olvidar la restauración y conservación del patrimonio arquitectónico de la ciudad antigua. Su labor abrirá el camino a los arquitectos posteriores que con criterios ya modernos se ocuparán de las tareas de alineación de calles y plazas y de los incipientes proyectos de ensanche.

32 Las descripciones proceden del texto ya citado de Alfonso Braojos Garrido (páginas $330-32$ ). 